\title{
Very-high-cycle fatigue behavior of Ti-6Al-4V manufactured by selective laser melting: Effect of build orientation
}

\author{
Guian Qian ${ }^{\mathrm{a}, \mathrm{b}}$, Yanfeng Li ${ }^{\mathrm{a}, \mathrm{b}}$, D.S. Paolino ${ }^{\mathrm{c}}$, A. Tridello ${ }^{\mathrm{c}}$, F. Berto ${ }^{\mathrm{d}}$, Youshi Hong ${ }^{\mathrm{a}, \mathrm{b}, *}$ \\ ${ }^{a}$ State Key Laboratory of Nonlinear Mechanics (LNM), Institute of Mechanics, Chinese Academy of Sciences, Beijing 100190, China \\ ${ }^{\mathrm{b}}$ School of Engineering Science, University of Chinese Academy of Sciences, Beijing 100049, China \\ ${ }^{c}$ Department of Mechanical and Aerospace Engineering, Politecnico di Torino, 10129 Turin, Italy \\ ${ }^{\mathrm{d}}$ Department of Mechanical and Industrial Engineering, Norwegian University of Science and Technology (NTNU), Richard Birkelands vei 2b, 7491 Trondheim, Norway
}

\section{A R T I C L E I N F O}

\section{Keywords:}

High-cycle fatigue (HCF)

Very-high-cycle fatigue (VHCF)

Selective laser melting (SLM)

Titanium alloy

Building direction

Fatigue design

\begin{abstract}
A B S T R A C T
The effect of building orientation on the very-high-cycle fatigue (VHCF) response of Ti-6Al-4V specimens produced through selective laser melting (SLM) process with three different building orientations $\left(0^{\circ}, 45^{\circ}\right.$ and $\left.90^{\circ}\right)$ has been experimentally assessed. The fatigue performance decreases with different building orientations from $0^{\circ}$ to $90^{\circ}$. The fatigue crack origin has been found to be always an internal defect both at high-cycle fatigue and VHCF regime independent of building orientations. Size of defects induced fatigue failures and the stress intensity factor range decrease with the number of cycles to failure. By considering the VHCF strength at $10^{9}$ cycles, the median value decreases from $217 \mathrm{MPa}\left(0^{\circ}\right)$ to $201 \mathrm{MPa}\left(45^{\circ}\right)$ and finally to $155 \mathrm{MPa}\left(90^{\circ}\right)$, with a $40 \%$ reduction from $0^{\circ}$ to $90^{\circ}$. The building orientation significantly influences both the defect size and the resulting VHCF response.
\end{abstract}

\section{Introduction}

Titanium alloys are widely used in aerospace and many other industrial applications due to their high specific strength, low density, high temperature and high corrosion resistance. Nevertheless, the traditional manufacturing processes of titanium alloys are difficult and expensive, due to their low thermal conductivity and chemical reactivity with tool materials (especially at elevated temperatures), which significantly reduces the service lifetime [1]. In recent years, the development of additive manufacturing (AM) processes that permit to minimize waste and to manufacture complex shapes [2-6], has provided a cost-effective alternative to traditional manufacturing processes for titanium alloys. However, there are still some issues concerning the structural integrity of titanium alloy components produced by different AM techniques. The experimental assessment of the mechanical properties of AM titanium alloys is needed to understand their failure mechanisms and to ensure a safety design. So far, many experimental tests have been carried out to investigate the quasi-static mechanical properties [6-8] and the high-cycle fatigue (HCF) response [9-12] of AM titanium alloys, particularly the widely used Ti-6Al-4V alloys. However, few results are available on the very-high-cycle fatigue (VHCF) behavior [13-15]. For example, in [13], the effect of a stress relief heat treatment and a hot-isostatic pressing (HIP) process was investigated; in
[14], experimental tests were carried out on the mechanical properties of specimens produced by SLM and electron beam melting (EBM) processes; whereas, in [15], fatigue tests up to $10^{9}$ cycles were performed on specimens with large loaded volume to investigate size-effects. The effect of building orientation on the VHCF response of Ti-6Al$4 \mathrm{~V}$ alloy has not been investigated yet, even though it is well-known that it significantly affects related mechanical properties and defect distribution [7].

In the present paper, the effect of building orientation on the VHCF response of Ti-6Al-4V specimens produced by an SLM process was assessed experimentally and investigated in a statistical framework according to the models proposed in [16-20]. Fully reversed tensioncompression ultrasonic fatigue tests were performed on the specimens produced with three different building orientations $\left(0^{\circ}, 45^{\circ}\right.$ and $\left.90^{\circ}\right)$. Fracture surfaces were observed with scanning electron microscopy (SEM). The crack origin and crack nucleation processes in the AM Ti$6 \mathrm{Al}-4 \mathrm{~V}$ alloys were compared with those typical in a traditionally manufactured Ti-6Al-4V alloy as reported in [21-25]. In particular, the results in [21-24] showed that, for conventional forged titanium alloy in both VHCF and HCF regimes, cracks initiate from the surface for stress ratio $\mathrm{R}=-1$; whereas, the crack origin is from subsurface or internal, with a coarser rough area (RA) around the crack origin and a fish-eye (FiE) zone on the fracture surfaces experienced $R \neq-1$.

\footnotetext{
* Corresponding author.

E-mail address: hongys@imech.ac.cn (Y. Hong).
} 


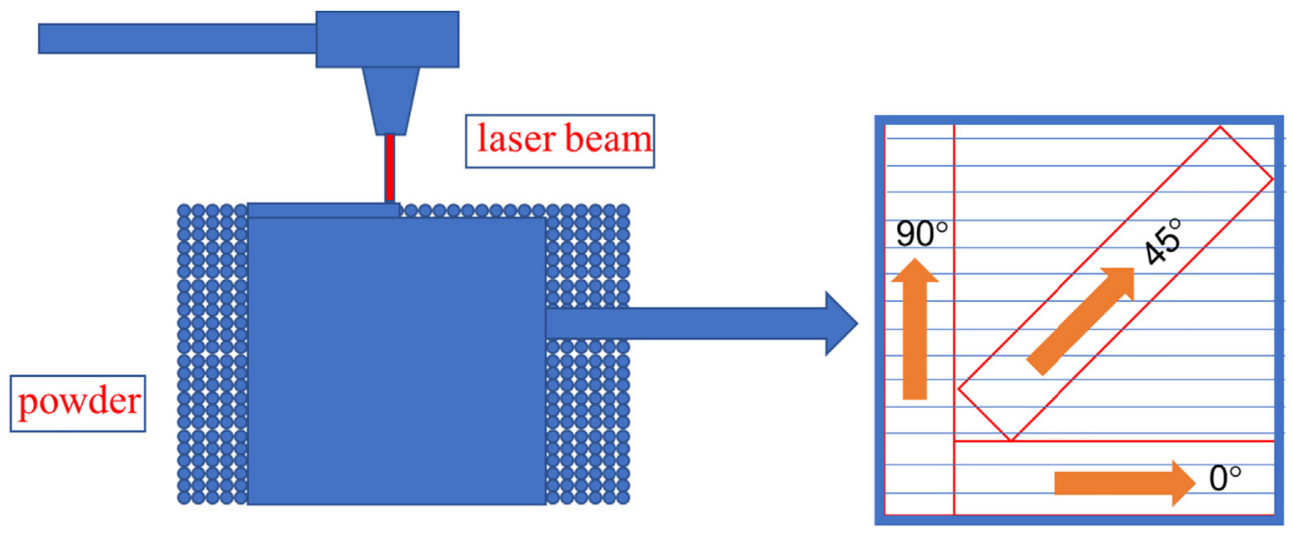

Fig. 1. Schematic drawing of parts manufactured by SLM.

\section{Specimen preparation and test procedure}

\subsection{Material}

The material tested is Ti-6Al-4V which is an $\alpha+\beta$ type titanium alloy [23]. The $\alpha$ phase is a hexagonal close-packed (HCP) crystal structure and the $\beta$ phase is a body-centered cubic (BCC) structure. The tensile property and ductility of the $\alpha+\beta$ type titanium alloy are usually very good for load bearing applications. The specimens were made by SLM. Different building directions of the specimens were prepared by cutting in different directions from the bulk $3 \mathrm{~d}$ printed material (Fig. 1). Some recent papers have extensively discussed the presence of surface defects on the specimens directly obtained by SLM $[3,5,6,24,25]$. Due to the process employed in the present work for manufacturing the samples, the defects are not concentrated on the surfaces but well distributed inside the specimens.

The typical microstructure of Ti-6Al-4V made by SLM, as shown in Fig. 2, is characterized by a lamellar structure that is different from the common microstructure of Ti-6Al-4V obtained by traditional manufacturing methods. This difference is mainly due to the repeated melting and solidification between layers, which is typical in the SLM process (Fig. 2) $[26,27]$. Because of the printing mode in SLM, the density of defects in the material increases [4]. Surface and internal pores are the main type of defects in the investigated material (Ti-6Al$4 \mathrm{~V}$ ) obtained by SLM.

The specimens were made with different building orientations $\left(0^{\circ}\right.$, $45^{\circ}$ and $90^{\circ}$ ). However, as the angle of building direction increases, the grains of the dark color area become finer (Fig. 2a-c). In Ref. [11], the porosity difference due to print orientation is explained by considering the overhang structure formed during the manufacturing process. It is shown that the overhang structure will lead to more defects if the manufactured specimen is neither perpendicular nor parallel to the substrate. In addition, across printing layer may result in more defects too. As a result, defect density of specimen manufactured at $45^{\circ}$ is higher. In our paper, the specimen which was used for statistics of defect density was built perpendicular to the load direction. It is observed that the defect density distribution is in agreement with that in Ref. [11]. This confirms that our results agree with those recently reported in [11]. Consistently with that work, the density of defects also varies with building orientations, which is lower at $45^{\circ}$ than that at $90^{\circ}$ and $0^{\circ}$. The size and position of defects influence not only the static tensile property but also the fatigue performance, which is very
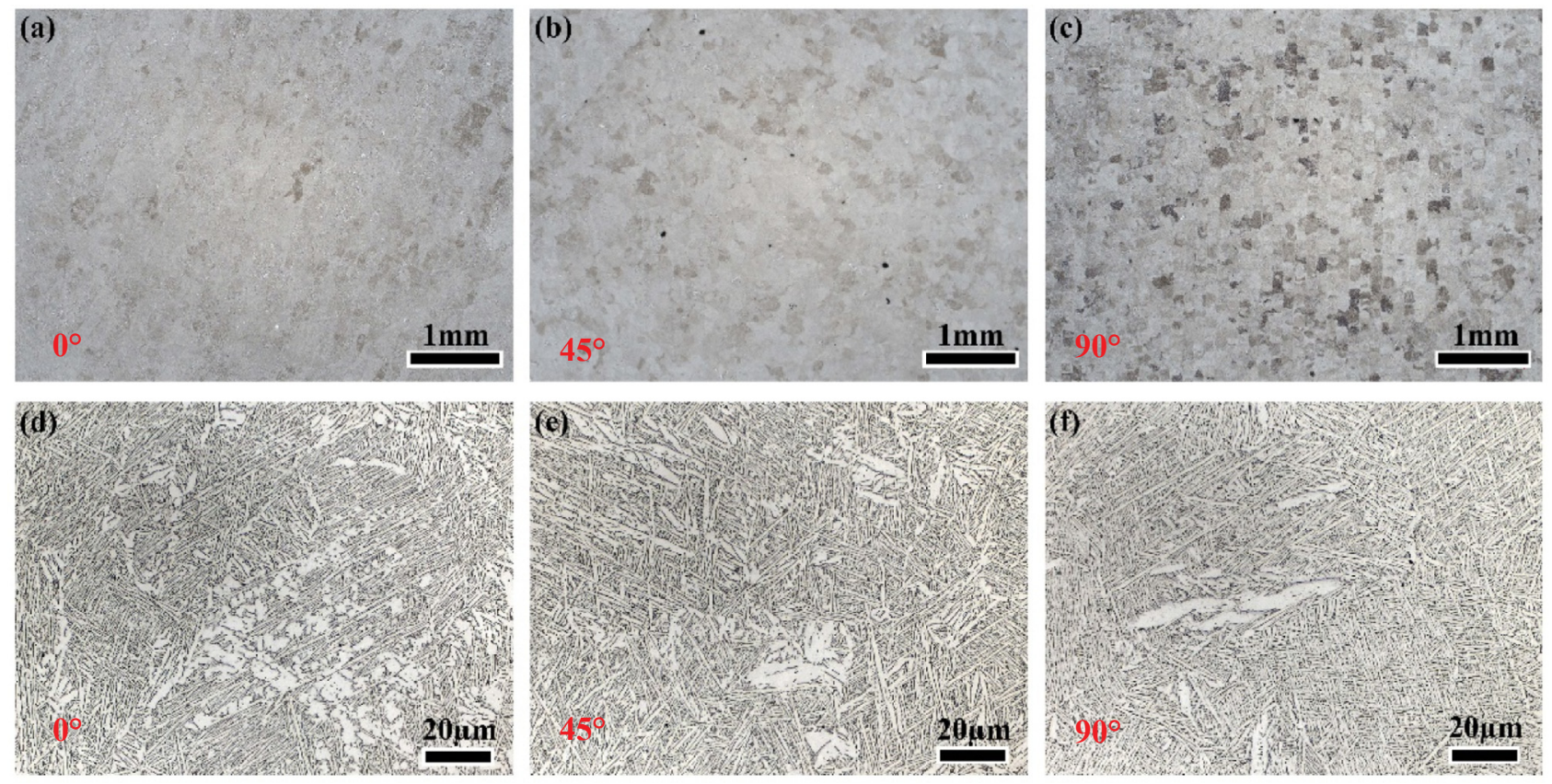

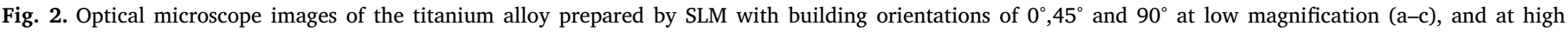
magnification (d and e). 


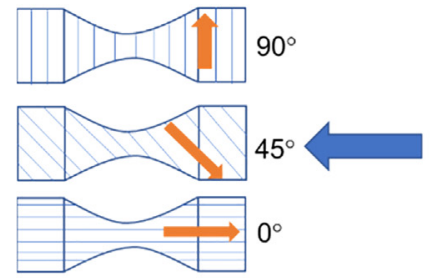

(a)

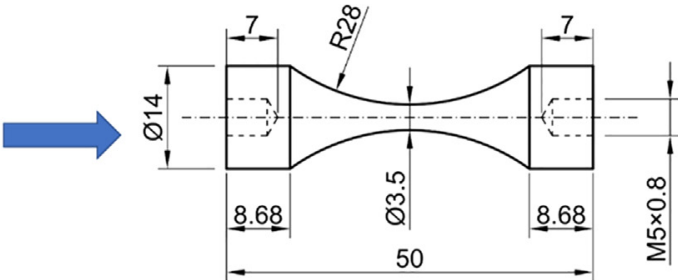

(b)

Fig. 3. Specimen shape and dimension (a) and schematic drawing of specimens with different building orientations (b) for ultrasonic fatigue testing.

(a)

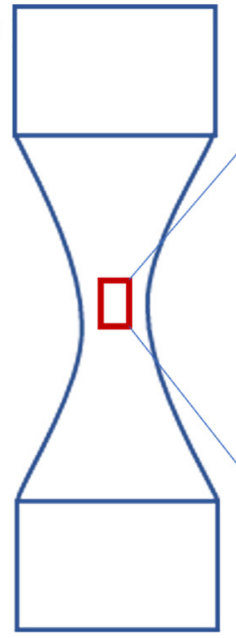

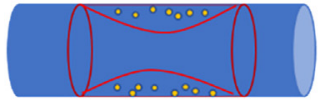

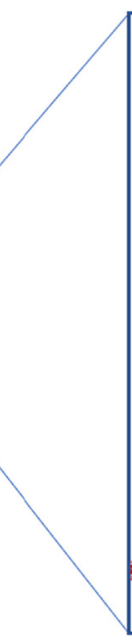

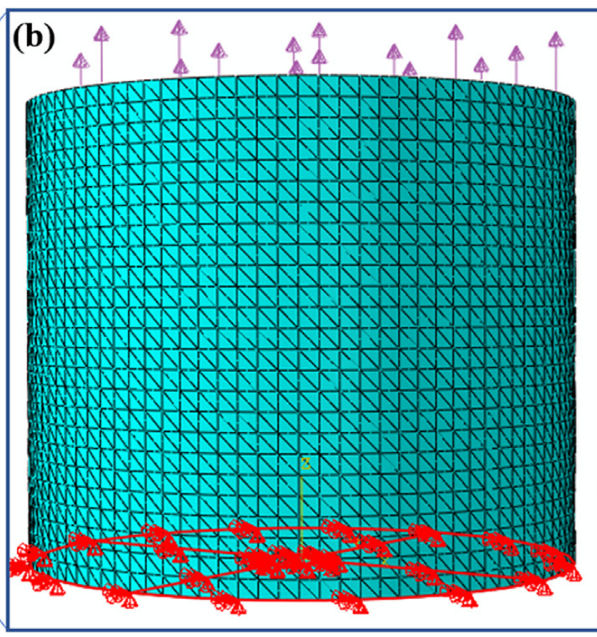

(c)

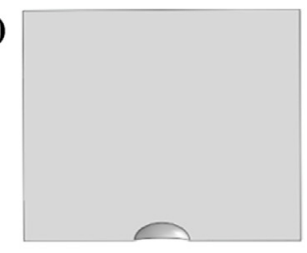

(d)

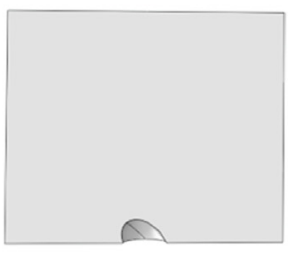

(e)

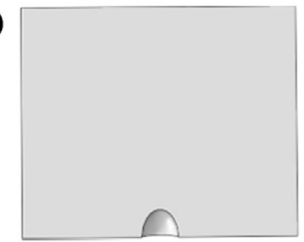

Fig. 4. Geometric model for finite element modeling. (a and b) Schematic of building finite element model. (c-e) Cross profiles of the geometric model with a defect oriented at $0^{\circ}, 45^{\circ}$ and $90^{\circ}$.

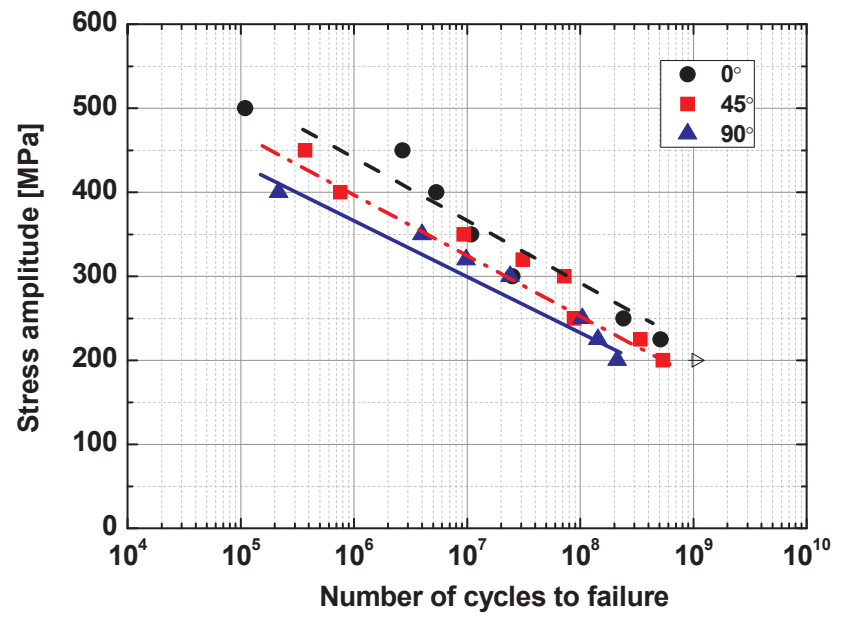

Fig. 5. S-N data of Ti-6Al-4V specimens manufactured with three different building orientations.

important for practical engineering applications.

\subsection{Specimen and fatigue test}

Fatigue tests at $R=-1$ were carried out by using an ultrasonic fatigue tester (Lasur GF20-KT) with a frequency of $20 \mathrm{kHz} \pm 500 \mathrm{~Hz}$ at room temperature in air. The specimen geometry is depicted in Fig. 3. As previously explained and as also mentioned in [24], the specimens directly obtained by SLM usually are characterized by a large number of defects on the surface. This is not the case in the present work, in which the specimens were obtained by cutting the bulk material in the desired directions.

Traditional fatigue tests are generally performed up to $10^{7}$ cycles due to limitations of test equipment and fatigue limit. But there is an increase of evidence that a large amount of materials also exhibit VHCF behavior. Ultrasonic fatigue testing can substantially shorten the time of tests, allowing to increase the number of cycles that can be easily reached in a test. The ultrasonic fatigue testing machine is made of an ultrasonic signal generator, a piezoelectric transducer, and an amplitude amplifier. For high-strength titanium alloys, the loading frequency does not significantly impact the overall fatigue performance.

\subsection{Fracture surface observations}

The fracture surfaces were observed by using SEM and scanning white light interferometry (SWLI). From the images taken with SEM, the morphology of a crack in the initiation phase and propagation phase was investigated. In addition, the shape of the defects inducing fatigue crack initiation was analyzed. The optical microscope was used to observe the microstructure of samples. By using SWLI, additional information on the morphology of fracture surfaces and of defect configurations was obtained. The size and depth of defects were measured by using a post-processing software Image Proplus 6.0.

\subsection{Finite element modeling}

Finite element method was employed to evaluate stress 

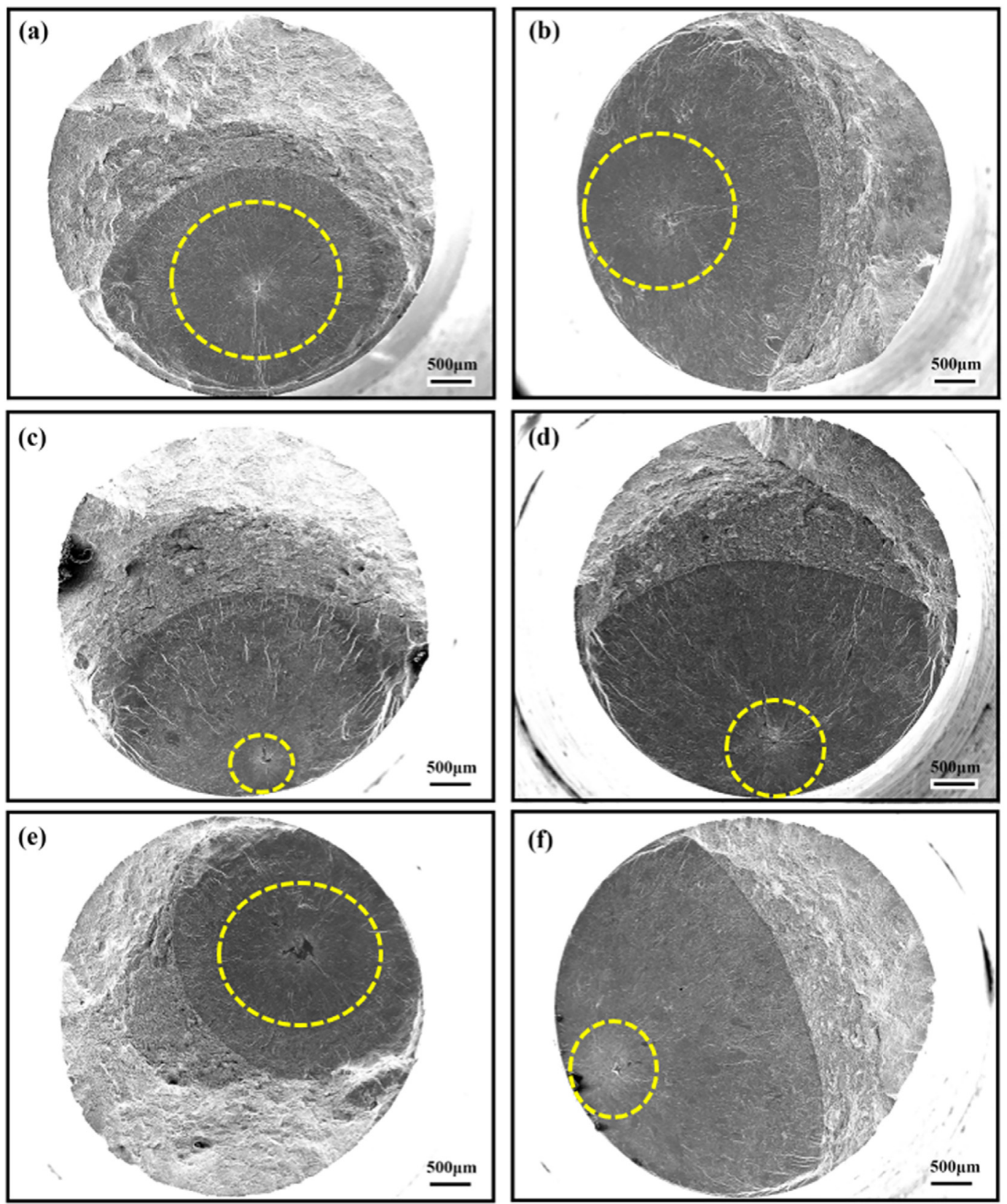

Fig. 6. Fractography of Ti-6Al-4V specimens manufactured with three building orientations. (a) $0^{\circ}, \sigma_{\mathrm{a}}=450 \mathrm{MPa}$ and $N_{\mathrm{f}}=2.68 \times 10^{6}$; (b) $0^{\circ}, \sigma_{\mathrm{a}}=300 \mathrm{MPa}$ and $N_{\mathrm{f}}=2.51 \times 10^{7} ;$ (c) $45^{\circ}, \sigma_{\mathrm{a}}=450 \mathrm{MPa}$ and $N_{\mathrm{f}}=3.7 \times 10^{5}$; (d) $45^{\circ}, \sigma_{\mathrm{a}}=320 \mathrm{MPa}$ and $N_{\mathrm{f}}=3.1 \times 10^{7} ;$ (e) $90^{\circ}, \sigma_{\mathrm{a}}=400 \mathrm{MPa}$ and $N_{\mathrm{f}}=2.15 \times 10^{5} ;$ (f) $90^{\circ}$, $\sigma_{\mathrm{a}}=250 \mathrm{MPa}$ and $N_{\mathrm{f}}=1.03 \times 10^{8}$.

concentration factors due to the presence of the defects to initiate fatigue cracks. Abaqus code was employed for this purpose. Usually a clear relationship between the defects and the load orientation in specimens obtained by traditional technologies is difficult to identify. On the contrary, for the specimens obtained by SLM with different building orientations, the stress distribution beside the defects changes as a function of the defect shape and the load direction. A cylinder model with the diameter of $200 \mu \mathrm{m}$ and the height of $200 \mu \mathrm{m}$ which simulates a part of the whole specimen was established (Fig. 4a and b). A constant remote stress of $200 \mathrm{MPa}$ was applied on the top surface of the model and the symmetry conditions were set on the bottom side. An ellipsoid with the major axis of $25 \mu \mathrm{m}$ and short axis of $40 \mu \mathrm{m}$ was modeled. This size is in good agreement with the size of the defects detected in the specimens. The defect orientation changes from specimen to specimen as a function of building orientation. The cross-sectional profile of the three different finite element models corresponding to building orientations of $0^{\circ}, 45^{\circ}$ and $90^{\circ}$ are shown in Fig. $4 \mathrm{c}-\mathrm{e}$.

\section{Fatigue property and fractography}

\section{1. $S-N$ data}

Three groups of specimens were prepared with respect to the three building orientations, which were used for ultrasonic fatigue testing. All the fatigue tests were performed at $R=-1$. Fig. 5 shows the stress amplitude $\sigma_{\mathrm{a}}$ as a function of the number of cycles to failure $N_{\mathrm{f}}$. The range of stress amplitude $\sigma_{\mathrm{a}}$ in HCF and VHCF regimes varies from 200 to $500 \mathrm{MPa}$ and a fatigue limit does not appear for all three configurations. The fatigue strength of specimens manufactured at $0^{\circ}$ is the highest, followed by those manufactured at $45^{\circ}$ and $90^{\circ}$. In HCF regime the difference among the three orientation specimens is evident but there is almost a negligible difference in the VHCF regime. In HCF 

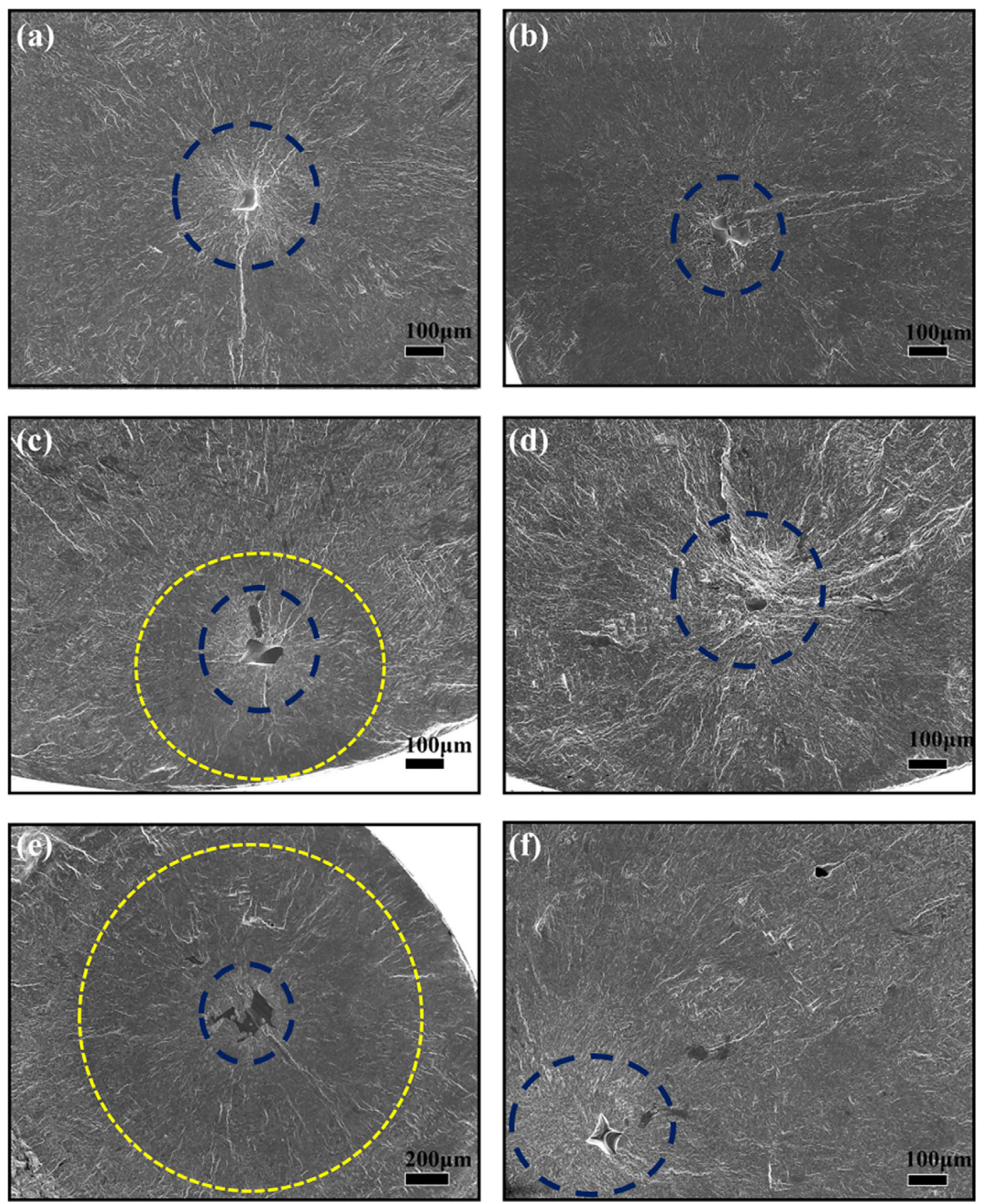

Fig. 7. FiE and crack origins for specimens manufactured with three different orientations. (a) $0^{\circ}, \sigma_{\mathrm{a}}=450 \mathrm{MPa}$ and $N_{\mathrm{f}}=2.68 \times 10^{6}$; (b) $0^{\circ}, \sigma_{\mathrm{a}}=300 \mathrm{MPa}$ and $N_{\mathrm{f}}=2.51 \times 10^{7}$; (c) $45^{\circ}, \sigma_{\mathrm{a}}=450 \mathrm{MPa}$ and $N_{\mathrm{f}}=3.7 \times 10^{5}$; (d) $45^{\circ}, \sigma_{\mathrm{a}}=320 \mathrm{MPa}$ and $N_{\mathrm{f}}=3.1 \times 10^{7}$; (e) $90^{\circ}, \sigma_{\mathrm{a}}=400 \mathrm{MPa}$ and $N_{\mathrm{f}}=2.15 \times 10^{5}$; (f) $90^{\circ}$, $\sigma_{\mathrm{a}}=250 \mathrm{MPa}$ and $N_{\mathrm{f}}=1.03 \times 10^{8}$. Blue dashed ring shows the RA and yellow dashed ring shows the FiE. (For interpretation of the references to color in this figure legend, the reader is referred to the web version of this article.)

regime, the defect and the strength of material are the most important factors affecting the fatigue life and strength. In contrast, in VHCF regime, since the fine granular area (FGA) in the crack origin consumes most of fatigue life, the load amplitude and the material microstructure play also an important role, together with defect size. Specimens manufactured with SLM with different directions may have similar microstructure. However, their strength and defect distribution are quite different. As a result, the difference of fatigue strength among all the specimens is more pronounced in HCF regime but, mainly due to the similar microstructure, is less marked in VHCF regime. The S-N data do not display stepwise shape for all the three types of specimens, which is attributed to the fact that the internal crack initiation dominates in crack initiation of all the specimens. Thus, no transition of crack initiation from surface to subsurface in the regime from HCF to VHCF, resulting in the continuously descending shape of S-N curves.

\subsection{Crack origin observations}

Fracture surfaces were studied with SEM, as shown in Fig. 6a-e. Fig. $6 \mathrm{a}, \mathrm{c}$ and e show the fractography of specimens manufactured with building orientations of $0^{\circ}, 45^{\circ}$ and $90^{\circ}$ and failed in HCF regime. In $[13,14]$, fatigue crack of Ti-6Al-4V manufactured by casting starts from surface since its microstructure is equiaxed and contains no defect. However, in this study, for all Ti-6Al-4V specimens manufactured with three building orientations, fatigue crack initiation is from interior even in HCF regime. Fig. $6 \mathrm{~b}, \mathrm{~d}$ and $\mathrm{f}$ show the fractography in VHCF regime 
(a)

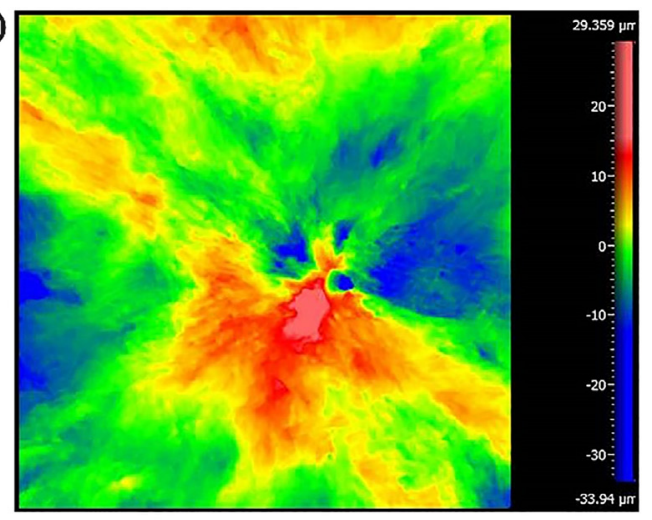

(c)

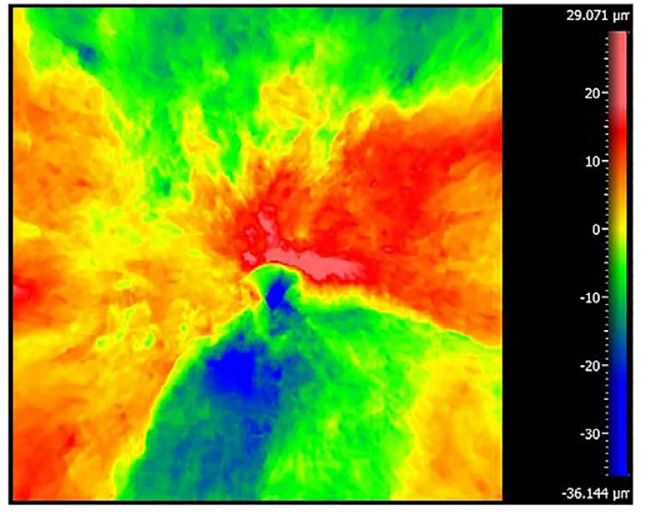

(e)

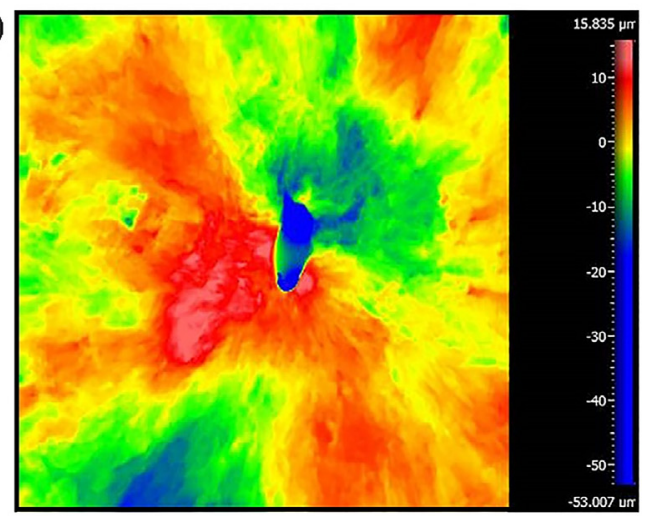

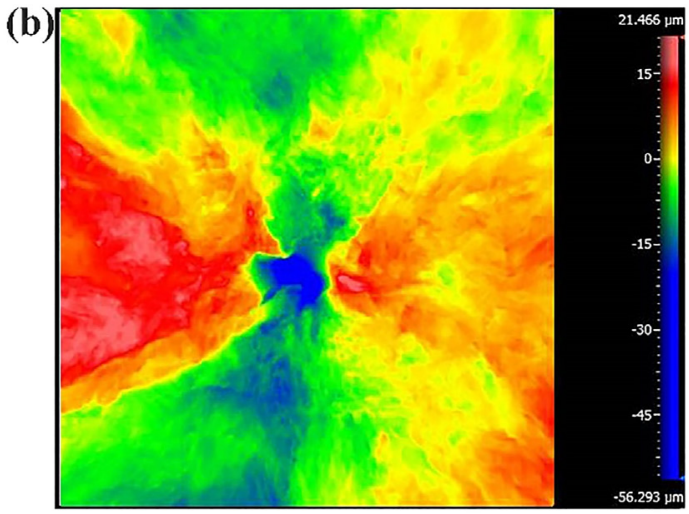

(d)

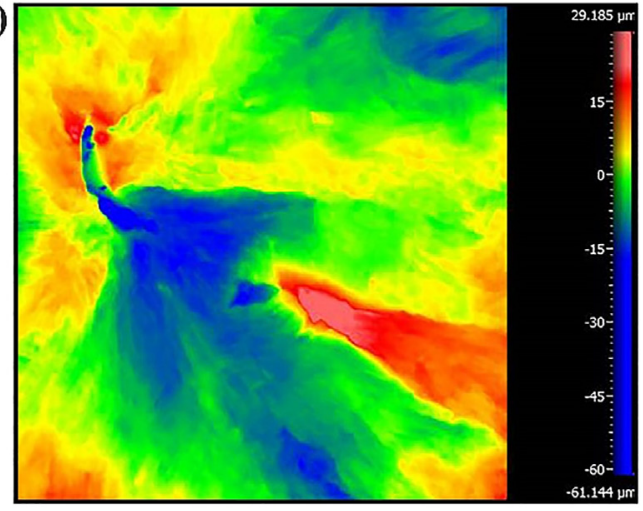

(f)

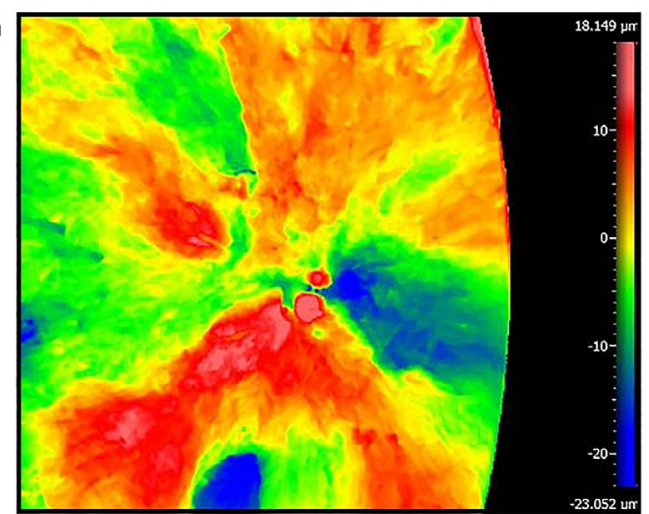

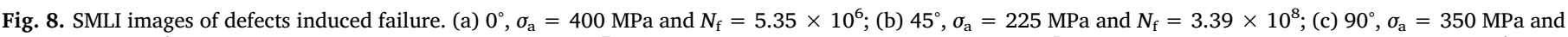
$N_{\mathrm{f}}=3.99 \times 10^{6}$; (d) $0^{\circ}, \sigma_{\mathrm{a}}=300 \mathrm{MPa}$ and $N_{\mathrm{f}}=2.51 \times 10^{7}$; (e) $45^{\circ}, \sigma_{\mathrm{a}}=400 \mathrm{MPa}$ and $N_{\mathrm{f}}=7.55 \times 10^{5}$; (f) $90^{\circ}, \sigma_{\mathrm{a}}=320 \mathrm{MPa}$ and $N_{\mathrm{f}}=9.81 \times 10^{6}$.

for the specimens manufactured at $0^{\circ}, 45^{\circ}$ and $90^{\circ}$. It is clear that crack initiation in VHCF regime is similar to that in HCF regime. As described previously, due to the same subsurface induced failure in HCF and VHCF regimes, no stepwise type of S-N data is shown.

Fig. 7 shows the crack origins and FiE patterns of six specimens manufactured with three different orientations. As mentioned in Section 3.1, all the cracks initiated from the internal of the specimens in both HCF and VHCF regimes. This is different from the crack origins in traditional casting Ti-6Al-4V. This may be due to the fact that a large number of internal porosity and lack of fusion exist inside the specimens manufactured by SLM. The internal crack initiation prevails in the competition over the surface crack initiation. It is seen that there is a rough area (RA) embracing the internal defect, which consumes most of fatigue lives and is the characteristic region of crack initiation in VHCF. An FiE pattern, which is a typical feature of crack early growth in VHCF regime, is formed outside the RA in HCF and VHCF in the specimens tested in this study. More studies on the formation and microstructure inside FiE are needed.

There is stress concentration around defects (such as inclusion or void) in the specimens subjected to cyclic loading. Fatigue crack normally initiates from this stress concentration area. It may grow slowly and form an RA due to numerous cyclic pressing (NCP) [24,28], and then lead to an FiE pattern. Thus, defect size generated in the process of $\mathrm{AM}$ in Ti-6Al-4V plays an important role in the fatigue performance.

\subsection{Fracture surface roughness}

The depth of fracture surface is not demonstrated in Section 3.2. In order to further study the crack origins, the fracture surface was analyzed by SWLI. Statistics on the defect depth of fatigue crack origins indicate that the depth of defect varies with the defect size. This is because that the defect of crack initiation in the additive manufactured $\mathrm{Ti}-6 \mathrm{Al}-4 \mathrm{~V}$ is often a near-spherical shape. In addition, the image interfered by SWIL can further show that there is a rough region near the 

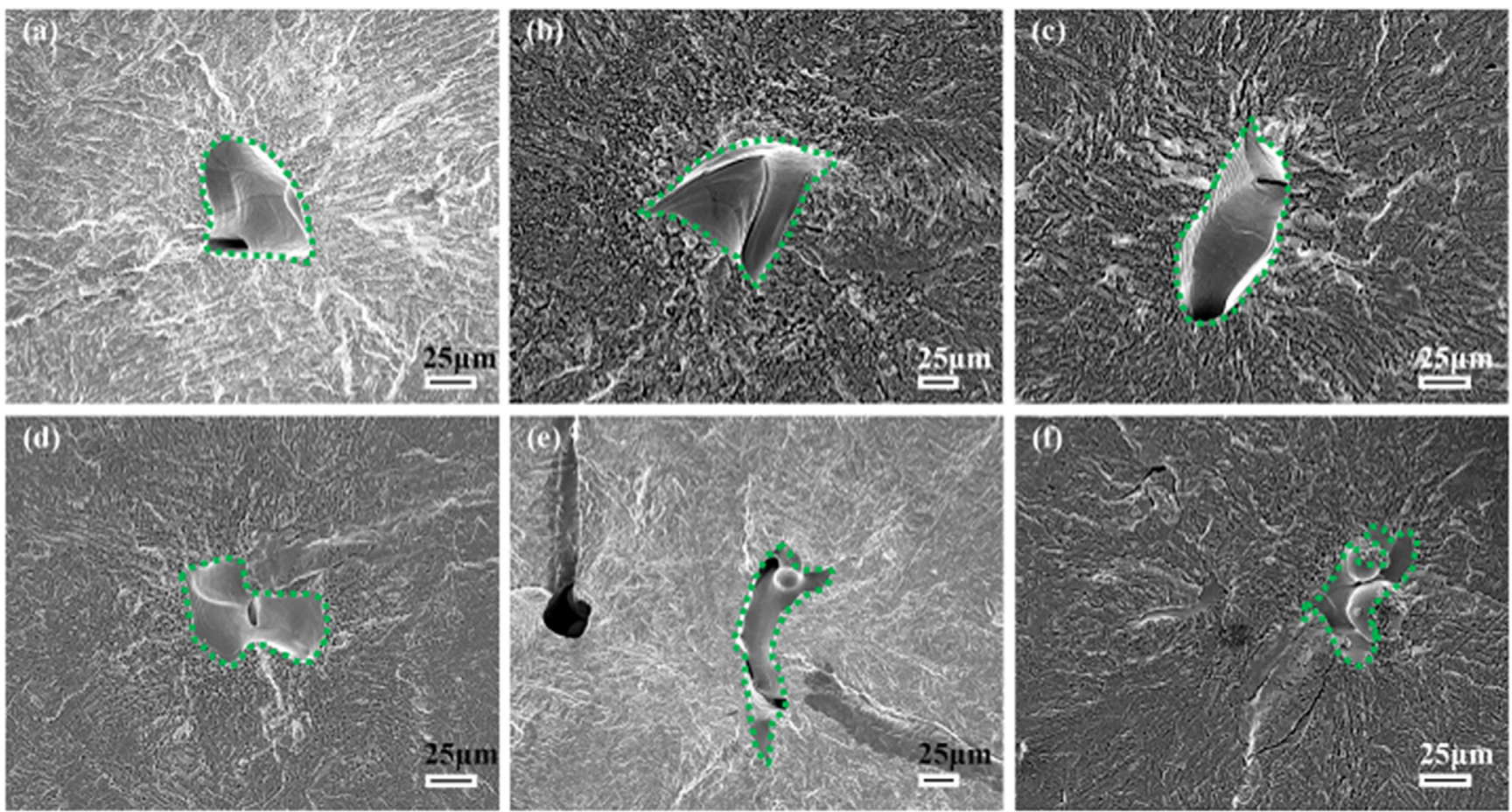

Fig. 9. SEM images of defects in the specimens. (a) $0^{\circ}, \sigma_{\mathrm{a}}=400 \mathrm{MPa}$ and $N_{\mathrm{f}}=5.35 \times 10^{6}$; (b) $45^{\circ}, \sigma_{\mathrm{a}}=225 \mathrm{MPa}$ and $N_{\mathrm{f}}=3.39 \times 10^{8}$; (c) $90^{\circ}$, $\sigma_{\mathrm{a}}=350 \mathrm{MPa}$ and $N_{\mathrm{f}}=3.99 \times 10^{6} ;$ (d) $0^{\circ}, \sigma_{\mathrm{a}}=300 \mathrm{MPa}$ and $N_{\mathrm{f}}=2.51 \times 10^{7}$; (e) $45^{\circ}, \sigma_{\mathrm{a}}=400 \mathrm{MPa}$ and $N_{\mathrm{f}}=7.55 \times 10^{5}$; (f) $90^{\circ}, \sigma_{\mathrm{a}}=320 \mathrm{MPa}$ and $N_{\mathrm{f}}=9.81 \times 10^{6}$.

crack initiation source region. Fig. 8 shows SMLI images of the defects which induced fatigue failure. The altitude decreases with color from red to blue. The altitude of defects is lower than its outside area, indicating that the defect is a void in material. The color of the area outside the defect is from red to green, indicating that this area is rough. The maximum value of altitude of the image ranges from 15 to $30 \mu \mathrm{m}$ and there is much green area in the image. By combining the images of SEM and SWLI, it can be shown that the fracture surface of specimen is a relatively rough area.

\section{Effects of internal defects}

Internal defects in Ti-6Al-4V affect the fatigue property. The defect size and depth are studied in this section. The relationship between defect size and location and fatigue life for the specimens manufactured with different orientations are discussed.

\subsection{Defect morphology}

With regard to the effect of defects on fatigue performance of Ti$6 \mathrm{Al}-4 \mathrm{~V}$, defects are classified into two types, i.e. regular and irregular ones. The regular defects, as shown in Fig. 9a-c, are the defects with regular shape but without nonmetallic inclusions. The others, as shown in Fig. 9d-f, are the irregular ones. The formation and propagation of these defects during VHCF need to be studied in depth. However, it shows no relation between the defect shape and the building orientation of the specimens. This may be because that the defect shape will change during fatigue test. The fatigue loading is a key paramter for the defect evolution during VHCF.

For further quantifying the depth of an internal defect, the altitude information for all specimens along a line (shown in Fig. 10a) which goes through the defect is gained from SWLI. The depth as a function of stress amplitude and number of cycles to failure is summarized in Fig. $10 \mathrm{~b}$ and c. There is no obvious relevance between the depth of defects and the stress amplitude or the number of cycles to failure. This is because that the appearance probability of defects inside the specimen is quite uniform. For $0^{\circ}$ specimen, the depth of defects ranges from 25 to $75 \mu \mathrm{m}$ while the depth has large dispersity in $45^{\circ}$ and $90^{\circ}$ specimens.

\subsection{Defect size distributions}

In Fig. 11a and b, the defect size with respect to the applied stress amplitude and the number of cycles to failure are plotted, respectively. In Fig. 11c the measured defect size, $\sqrt{a_{c}}$, is illustrated on a Gumbel plot. Moreover, according to $[16,17]$, the defect size is assumed to follow the largest extreme value distribution (LEVD). The estimated LEVD is also plotted in Fig. 11c.

The defect size of specimens was calculated with the tool of Proplus 6.0. Fig. $11 \mathrm{a}$ and $\mathrm{b}$ show the defect size versus the stress amplitude and the number of cycles to failure. In general, defect size increases with the increase of stress amplitude and the decrease of fatigue cycles. This is in agreement with the common practice that as the defect size increases, few fatigue cycles are needed to initiate and damage the specimen. For all three oriention specimens, the size of irregular defects is bigger than that of regular ones. According to Fig. 11c the defect size tends to increase with the building orientation: in particular, the defects that caused failures are larger in the specimens manufactured with a building orientation of $90^{\circ}$ and exhibit the largest scatter.

Fig. 12 shows the defect distance versus the number of cycles to failure and the stress amplitude. Fig. 12a shows the measured distance of defect site from surface. The distance indicates the distribution of defect on the fracture surface. The distance does not change with the number of cycles to failure or the stress amplitude. The defects in $0^{\circ}$ specimen are more near the centre of fracture surface, as shown in Fig. $12 \mathrm{~b}$ and $\mathrm{c}$.

\subsection{Stress intensity factor range of internal defects}

Combined the defect size of the crack origin with the magnitude of the applied stress, an equivalent stress intensity factor amplitude $\Delta \mathrm{K}$ can be obtained $[16,17]$, with its correlations with stress amplitude and 
(a)
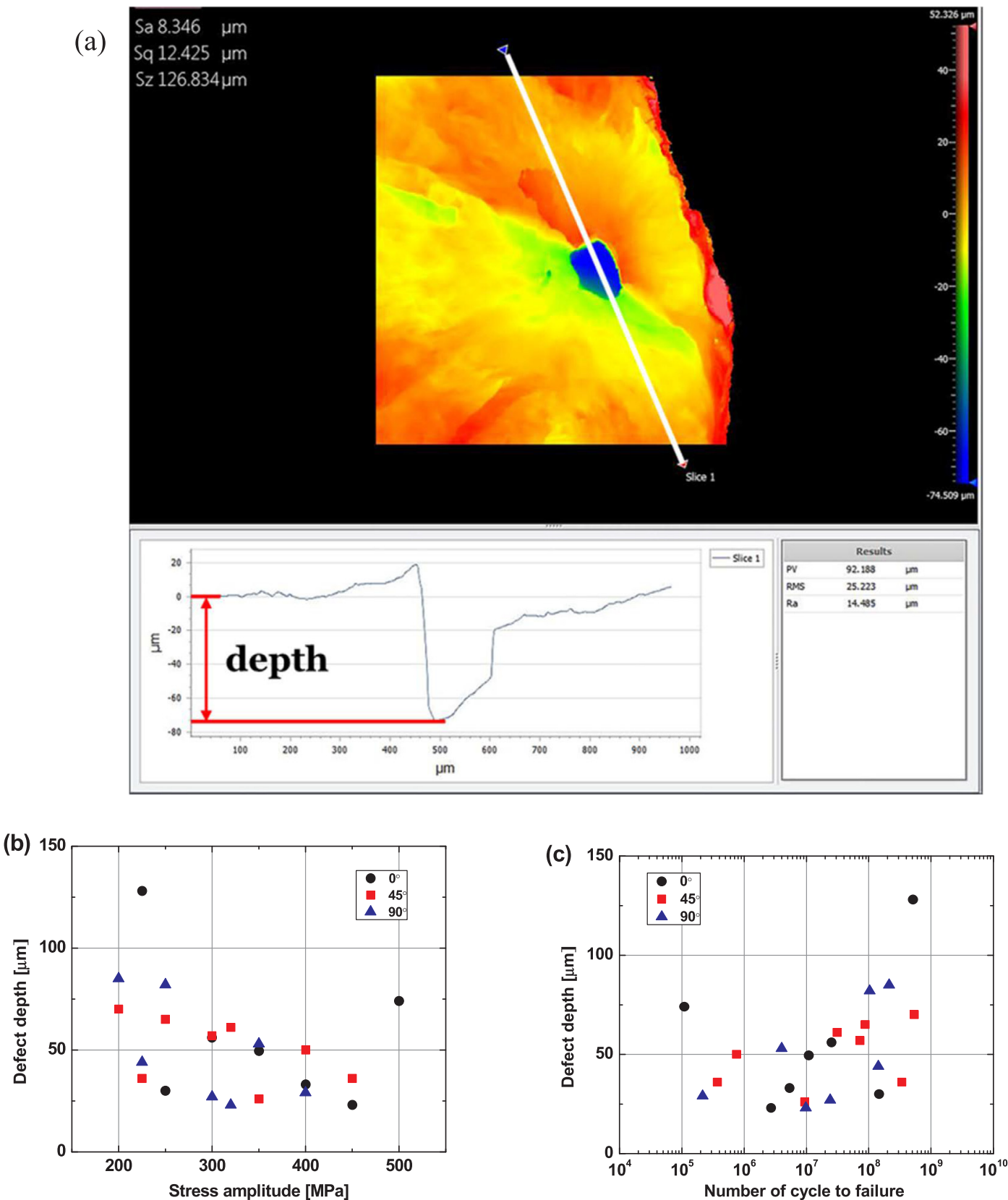

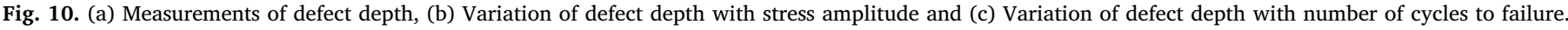

fatigue cycle being plotted in Fig. 13a and b. It is seen that, as the load cycle increases, the amplitude of the equivalent stress intensity factor range gradually decreases. In this case, the average size of the defects does not differ much. This result is similar to that for high-strength steels. Compared with the conventional Ti-6Al-4V fatigue test, the equivalent stress intensity factor range is stabilized near the fracture toughness with the increase of the load cycle, and the average size of defect gradually reduces. Although the size and depth of defects largely disperse, $\Delta K$ of defects which induced fatigue failure decreases with the decrease of stress amplitude and the increase of the number of cycles to failure without threshold value (Fig. 13). Fig. 13 shows that $\Delta K$ ranges in the sequence from high to low for $90^{\circ}, 45^{\circ}$ and $0^{\circ}$.

$\Delta K$ calculated by the size of defects and stress amplitude is a characteristic value for fatigue crack initiation. The number of cycles to failure is longer when the $\Delta K$ is low because the initiation of fatigue consumes most of fatigue life.

\subsection{Stress concentration}

The stress concentration was considered as the promoting factor in HCF and VHCF for traditional materials [10]. The stress concentration of the three different models with $0^{\circ}, 45^{\circ}$ and $90^{\circ}$ defect was determined by finite element method under the same load. Although the maximum stress appears in the cylinder with $45^{\circ}$ oriented defect because of the asymmetry of the defect with respect to the axial load, the area of high stress is smaller than the area of the models with $0^{\circ}$ and $90^{\circ}$ oriented defect. Stress value or the area of high stress of the model with $90^{\circ}$ defect is higher than that of the model with $0^{\circ}$ defect. For $0^{\circ}$ defect the high stress regime concentrates in the major axis of the ellipse. For $45^{\circ}$ defect stress concentration appears on a side of the elliptic section because of the deflection of defect. Because of the deeper and symmetrical defect under the axis load the high stress is distributed uniformly around the defect in $90^{\circ}$ defect model (Fig. 14).

Both the value and distribution of stress concentration affect the 

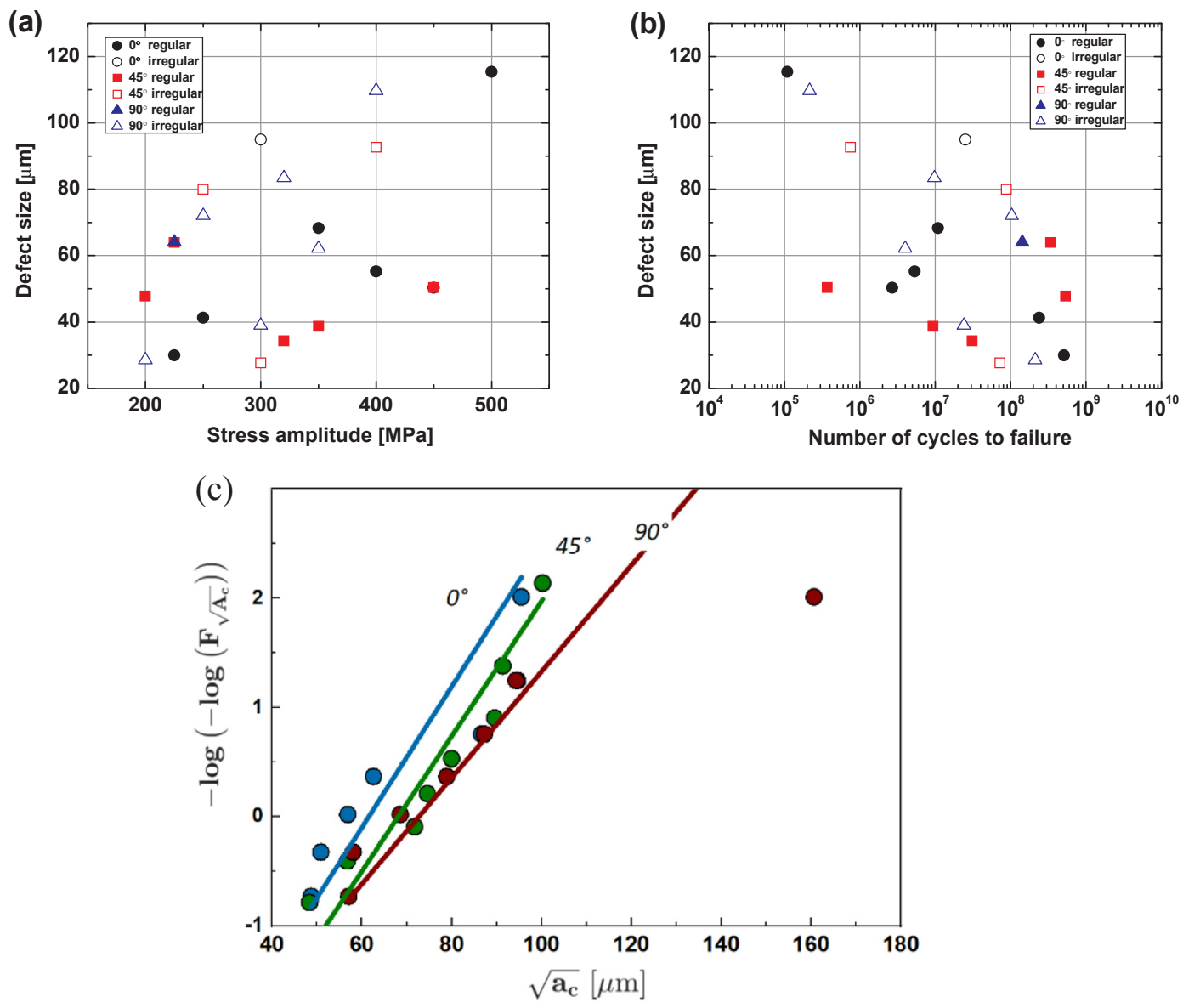

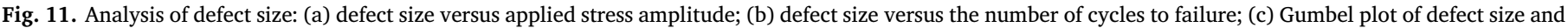
estimated LEVDs.

crack initiation in HCF and VHCF. Although there is no direct connection between the defect orientation and the build direction, stress concentration of the defect for the specimens with $0^{\circ}$ build direction is similar to that with $0^{\circ}$ build orientation.

\section{VHCF response: Effect of building orientation}

The effect of building orientation was further studied considering the P-S-N curves and the VHCF strength at $10^{9}$ cycles was analyzed. The marginal P-S-N curves, which take into account the defect size distribution (Section 4.2), were estimated according to the following model [16-20]:

$F_{Y}(y ; x)=\int_{0}^{\infty} \Phi\left(\frac{y-\mu_{Y}\left(x, \sqrt{a_{d 0}}\right)}{\sigma_{Y}}\right) \frac{\varphi_{L E V}\left(\frac{\sqrt{a_{d 0}}-\mu \sqrt{A}}{\sigma_{\sqrt{A}}}\right)}{\sigma_{\sqrt{A}}} d \sqrt{a_{d 0}}$

where:

$F_{Y}(y ; x)$ is the cumulative distribution function (cdf) of the finite fatigue life $Y=\log _{10}\left[N_{f}\right]$ (i.e., the fatigue life is the logarithm of the number of cycles to failure), and $x=\log _{10}\left[s_{a}\right]$;

$\Phi\left(\frac{y-\mu_{Y}\left(x, \sqrt{a_{d 0}}\right)}{\sigma \sigma_{Y}}\right)$ is the cdf of the normally distributed conditional finite fatigue life $Y \mid \sqrt{a_{d 0}}$ (i.e., the finite fatigue life for a given initial defect size), $\sqrt{a_{d 0}}$ the initial defect size, $\mu_{Y}\left(x, \sqrt{a_{d 0}}\right)=c_{Y}+m_{Y} x+n_{Y} \log _{10}\left[\sqrt{a_{d 0}}\right]$ and $\sigma_{Y}$ a constant parameter.

$f_{\sqrt{A}}\left(\frac{\sqrt{a_{d 0}}-\mu \sqrt{A}}{\sigma_{\sqrt{A}}}\right)$ is the probability density function (pdf) of the initial defect size $\sqrt{A}$, which follows an LEVD with parameters $\mu_{\sqrt{A}}$ and

$$
\sigma_{\sqrt{A}}
$$

Since no runout specimens are present, the constant coefficients of the mean fatigue life and the standard deviation were estimated by a multiple linear regression; whereas the constant coefficients of the LEVD were estimated through the application of the Maximum likelihood principle by considering the defect size data.

Fig. 15 shows the estimated P-S-N curves for the $0^{\circ}$ (Fig. 15a), the $45^{\circ}$ (Fig. 15b) and the $90^{\circ}$ (Fig. 15c) building orientation. In each figure, the median, the 0.25 -th and the 0.975 -th quantiles $(95 \%$ confidence interval) of the P-S-N curves are shown.

For a proper assessment of the effect of building orientation, the VHCF strengths at $10^{9}$ cycles (considered as representative of the VHCF response) have been estimated and compared. First, the pdfs of the fatigue strengths at $N_{f}=10^{9}$ cycles, estimated by deriving Eq. (1) with respect to $y$ and then by setting $y=9$ (i.e., $N_{f}=10^{9}$ ), are compared (Fig. 16a).

According to Fig. 16a, the VHCF strength at $10^{9}$ cycles decreases with the building orientation, from $217 \mathrm{MPa}\left(0^{\circ}\right)$ to $201 \mathrm{MPa}\left(45^{\circ}\right)$ and to $155 \mathrm{MPa}\left(90^{\circ}\right)$. The decrement is small from $0^{\circ}$ to $45^{\circ}$, about $7 \%$, whereas it is larger from $45^{\circ}$ to $90^{\circ}$ (about $23 \%$, considering the median value). In order to investigate if the difference is statistically significant, the empirical cumulative distribution functions (ecdfs) of the difference between the VHCF strength at $10^{9}$ cycles were also compared. For each building orientation, 10,000 values for the VHCF strength at $10^{9}$ cycles were simulated with the Monte Carlo method and, from the ecdfs of the differences between the VHCF strengths, the confidence intervals were estimated. Fig. 16b compares the ecdfs of the difference between the VHCF strengths for the three investigated building orientations: the 

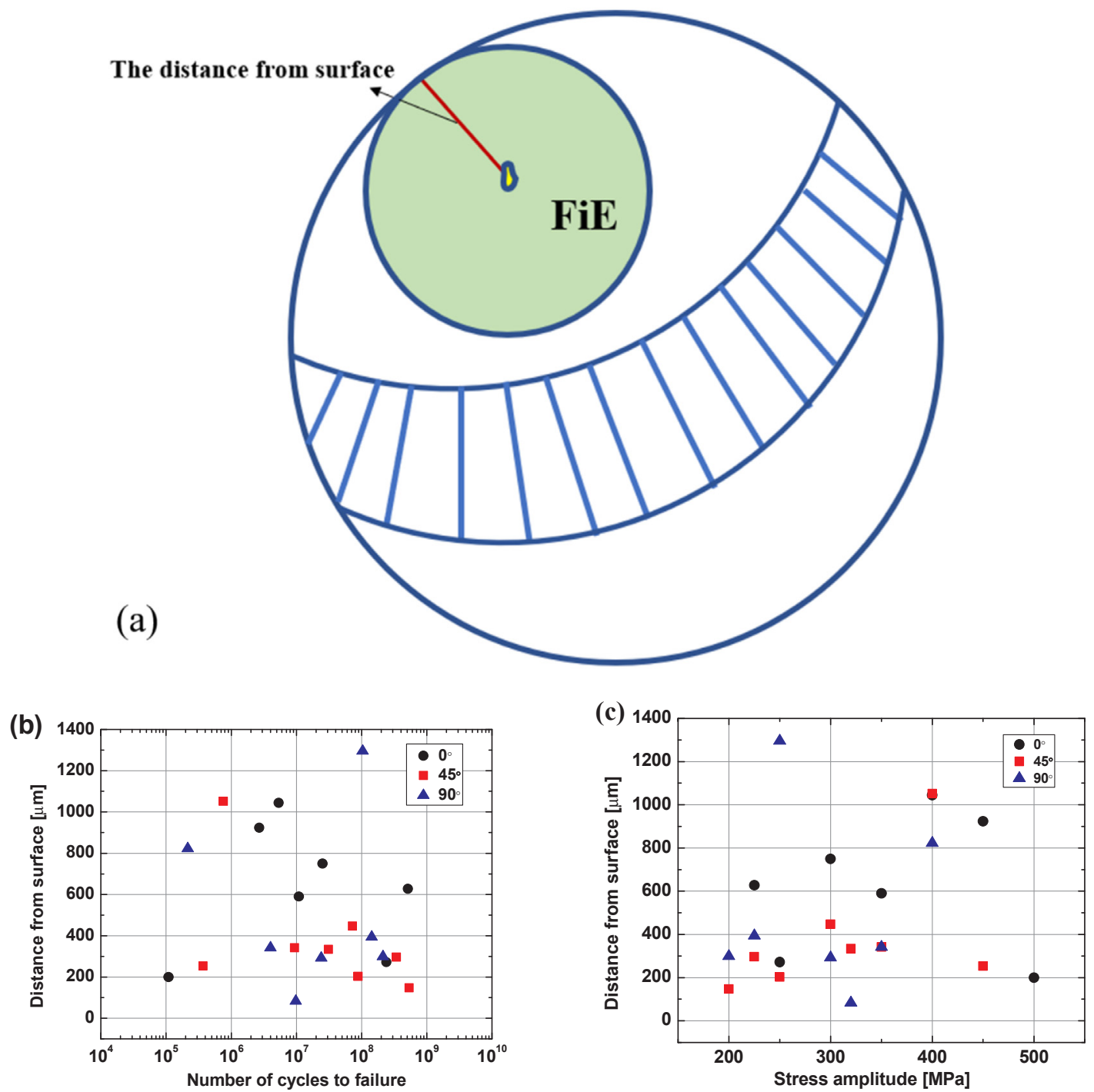

Fig. 12. Schematic drawing of distance of defect site from surface (a); and the distance from surface versus number of cycles to failure (b) and stress amplitude (c).
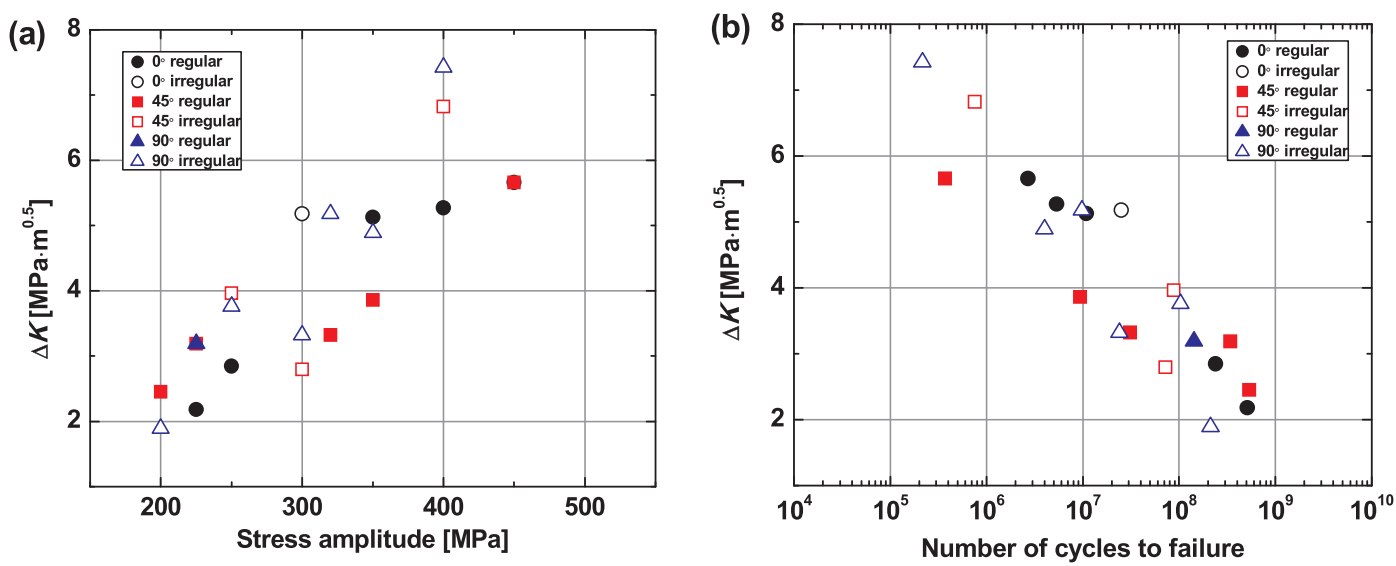

Fig. 13. The range of stress intensity factor versus (a) stress amplitude and (b) number of cycles to failure.

blue curve was estimated by considering the difference between the VHCF strength in the specimens manufactured at $0^{\circ}$ and $45^{\circ}$, the black curve by considering the building orientations at $45^{\circ}$ and $90^{\circ}$ and the green curve by considering the building orientations at $0^{\circ}$ and $90^{\circ}$.

According to Fig. 16b, it is found that there is no significant difference between the VHCF strengths of the specimens manufactured at $0^{\circ}$ and $45^{\circ}$ (the $10 \%$ quantile of the ecdf is below zero); whereas a significant difference exists if building orientations at $45^{\circ}$ and $90^{\circ}$ (the $10 \%$ quantile of the ecdf is positive and equal to 7.8 ) and at $0^{\circ}$ and $90^{\circ}$ (the $10 \%$ quantile of the ecdf is positive and equal to 13.9) are considered. However, by considering the pdfs of the VHCF strengths (Fig. 16a), a clear decreasing trend can be observed also between the 

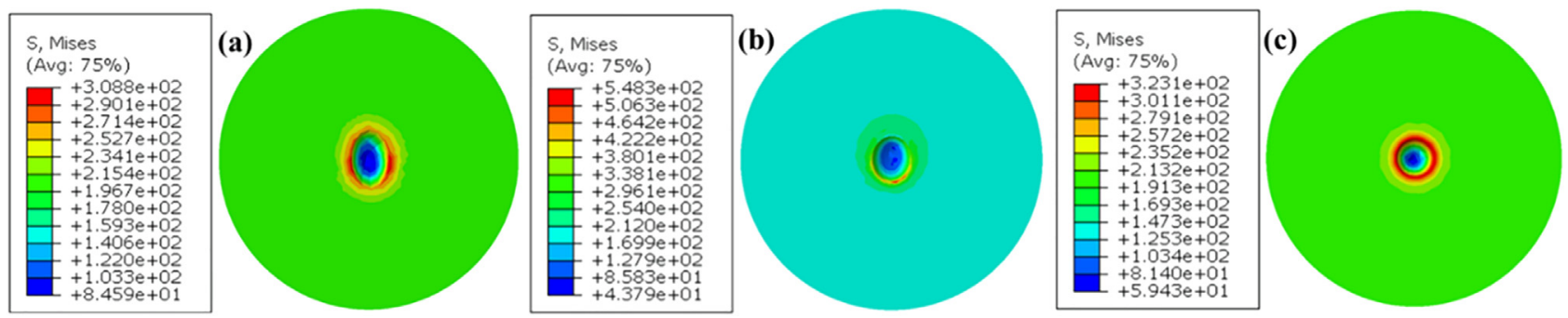

Fig. 14. Stress distribution of the three finite element models with $0^{\circ}, 45^{\circ}$ and $90^{\circ}$ defect.

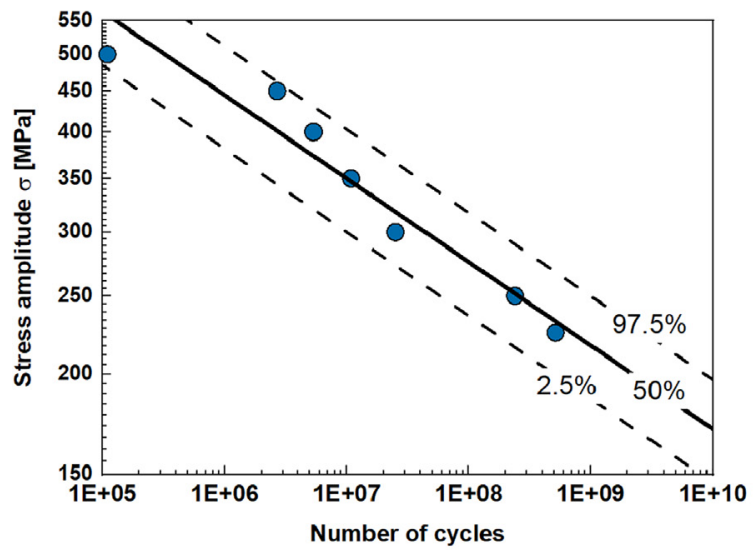

(a)

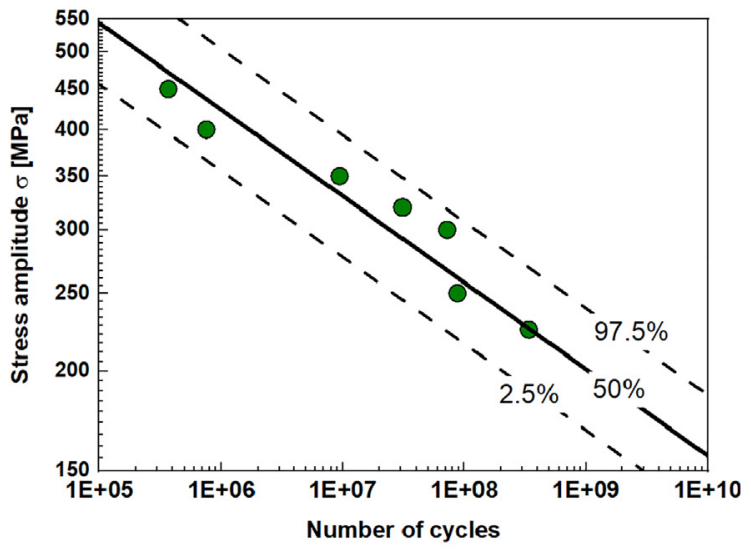

(b)

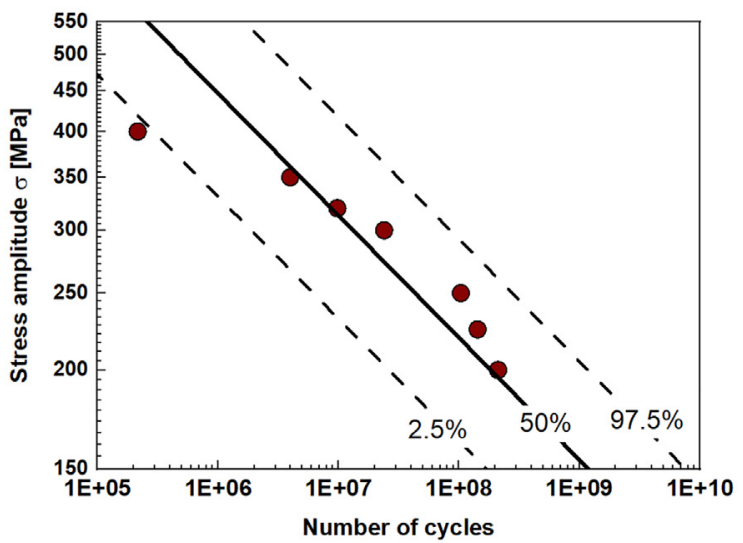

(c)

Fig. 15. P-S-N curves for the three investigated building orientations: (a) $0^{\circ}$; (b) $45^{\circ}$; (c) $90^{\circ}$.

VHCF strengths in the specimens manufactured at $0^{\circ}$ and $45^{\circ}$. Therefore, a further analysis was carried out. In particular, the decreasing trend of the VHCF strengths with respect to the building orientations was investigated in detail. In order to properly fit the decreasing trend between the VHCF strength and the building orientation, the corresponding VHCF strength at $10^{9}$ cycles was estimated for each experimental failure. Indeed, each specimen can be considered as a representative of a specific P-S-N curve. For the $i$-th specimen (tested at stress amplitude $s_{i}$ and failed after $n_{i}$ cycles), a specific probability value $\alpha_{i}$ can be computed from Eq. (1), by substituting $x$ with $\log _{10}\left(s_{i}\right)$ and $y$ with $\log _{10}\left(n_{i}\right)$. Given $\alpha_{i}$, the VHCF strength at $N_{f}=10^{9}$ for the $i$-th specimen can be easily obtained by solving Eq. (1) with respect to $x$ for $F_{Y}(y ; x)=\alpha_{i}$ and $y=9$. The procedure is schematically shown in Fig. 16c.

Given the VHCF strength at $N_{f}=10^{9}$ cycles for all the experimental failures, a quadratic model $y=a x^{2}+c, y$ being the VHCF strength and $x$ the building orientation, is proposed for modeling the dependency between the VHCF strength at $N_{f}=10^{9}$ cycles and the building orientation.

Fig. 16d shows the estimated quadratic model, together with the estimated experimental failures at $N_{f}=10^{9}$. According to Fig. 16d, the quadratic model well fits the experimental data: the coefficient of determination is equal to 0.7 , larger than that obtained with a linear model (about 0.6). The 95\% confidence interval for parameter $a$ was also estimated and found to be $[-0.010:-0.005]$. The zero value is not within the $95 \%$ confidence interval, thus proving that there is a significant dependency between the building orientation and the VHCF strength, even for building orientations of $0^{\circ}$ and $45^{\circ}$.

It is worth noting that the fatigue property and the approaches for the structural integrity assessment are an important topic for the additive manufactured alloys. Some existing methods for the study of traditional casting alloys and additively manufactured alloys may be applied for further studies considering the specific microstructural characteristics [29-37]. More comprehensive studies on the fatigue property of additive manufactured alloys are under preparation together with a large bulk of new test campaigns. Moreover, 


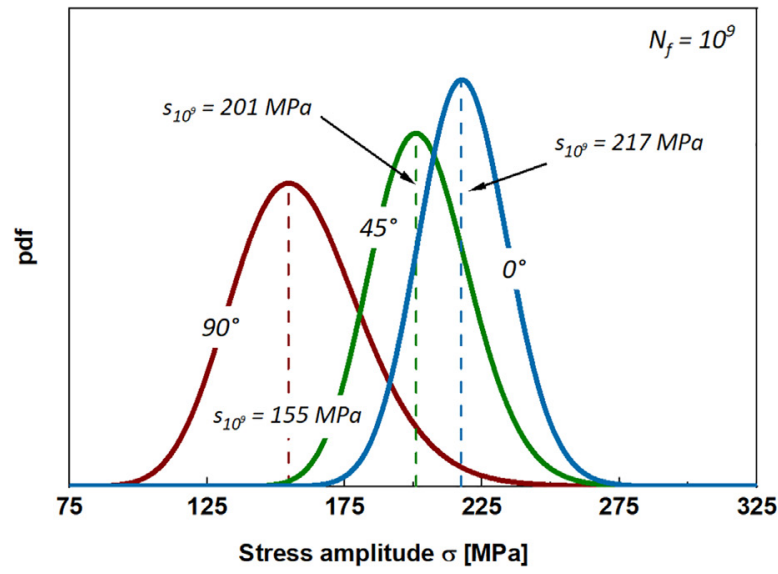

(a)

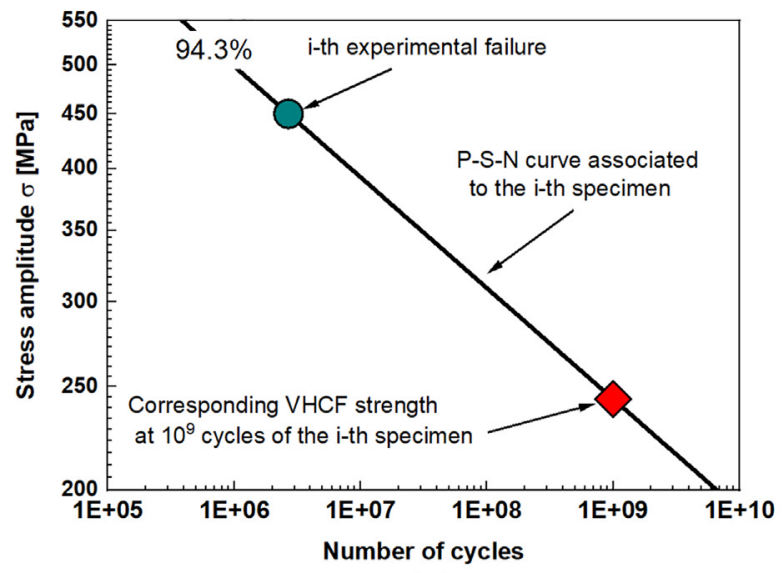

(c)

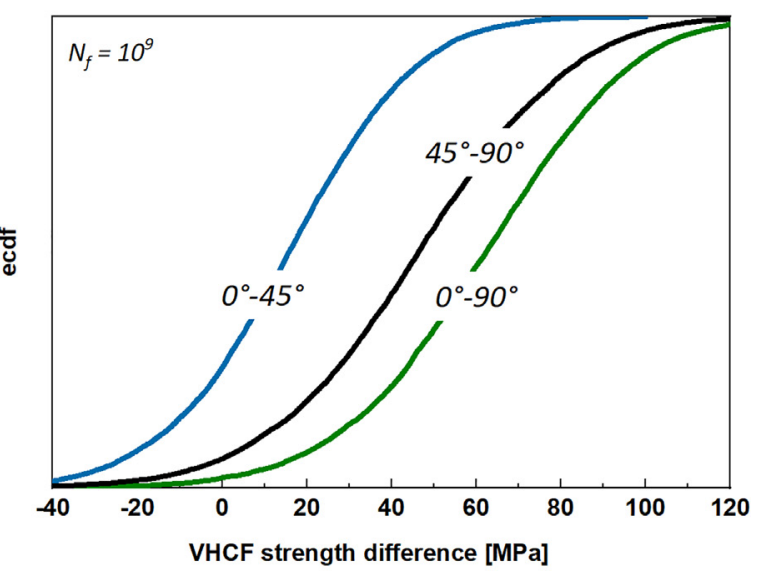

(b)

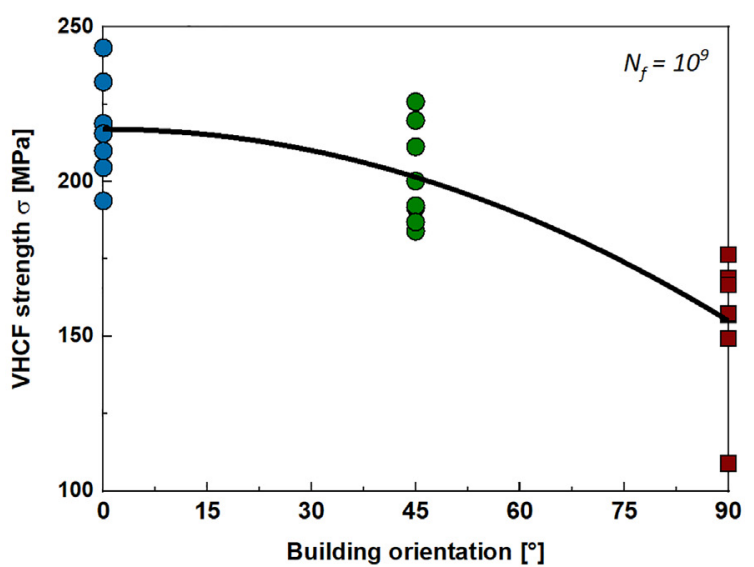

(d)

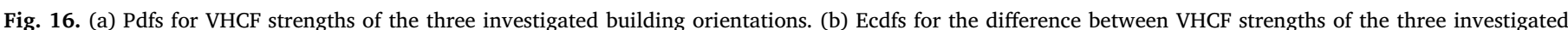

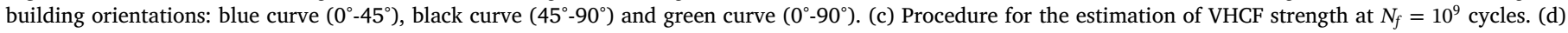

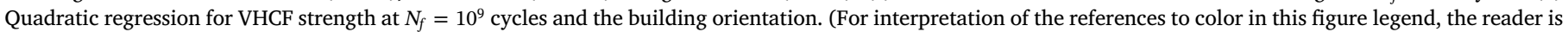
referred to the web version of this article.)

geometrically complex SLM parts are widely used in many industries for structural applications. It is common that complex SLM parts are subjected to cyclic loading. Fatigue strength is a fundamental property for engineering applications. In order to improve the fatigue strength of the parts, mechanical analysis should be first conducted by using finite element method to find the weaker points in the structure. Then building direction in the weaker locations should be properly chosen using the conclusion of the present study. As long as the building direction of the weaker locations is properly designed, the fatigue strength of whole complex SLM part will improve. Our results provide a hint for designing structures from perspective of build orientation. In a more in-depth study, this will also raise the question of structural design and optimization, which needs a further accurate investigation.

\section{Conclusions}

This work reports the fatigue behavior of the Ti-6Al-4V specimens manufactured by SLM with three building orientations. The density, size and position of defects in the specimens have been carefully analyzed. The following conclusions can be drawn:

(1) The fatigue performance decreases with different building orientations from 0 to $90^{\circ}$. The fatigue curves have the same slope at HCF and VHCF and for the different building orientations.

(2) The fatigue crack origin has been found to be always an internal defect both at HCF and VHCF regime independent of building orientations. RA and FiE have been observed on fracture surfaces both at $\mathrm{HCF}$ and VHCF regime.

(3) The size of defects induced fatigue failures decreases with the number of cycles to failure. The stress intensity factor range $\Delta K$ decreases with the increase of stress amplitude and the decrease of the number of cycles to failure. Moreover, defects are larger in the specimens manufactured with building orientation at $90^{\circ}$ and exhibit the largest scatter.

(4) The VHCF strength decreases with building orientation. By considering the VHCF strength at $10^{9}$ cycles, the median value decreases from $217 \mathrm{MPa}\left(0^{\circ}\right)$ to $201 \mathrm{MPa}\left(45^{\circ}\right)$ and finally to $155 \mathrm{MPa}$ $\left(90^{\circ}\right)$, with a $40 \%$ reduction from $0^{\circ}$ to $90^{\circ}$. A quadratic model has been proposed for fitting the dependency between the VHCF strength at $10^{9}$ cycles and the building orientation. The building orientation significantly affects the VHCF response.

\section{Declaration of Competing Interest}

The authors declare that they have no known competing financial interests or personal relationships that could have appeared to influence the work reported in this paper. 


\section{Acknowledgement}

This work was funded by the National Natural Science Foundation of China (No. 11872364, 11932020) and CAS Pioneer Hundred Talents Program.

\section{References}

[1] Leyens C, Peters M. Titanium and titanium alloys: fundamentals and applications Weinheim: Wiley-VCH; 2003.

[2] Prakash K, Nancharaih T, Nancharaih Rao V. Additive manufacturing techniques in manufacturing-an overview. Mater Today: Proc 2018;5:3873-82.

[3] Thijs L, Verhaeghe F, Craeghs T, Humbeeck J, Kruth J. A study of the microstructural evolution during selective laser melting of Ti-6Al-4V. Acta Mater 2010;58:3303-12.

[4] Yan W, Lin S, Kafka O, Yu C, Liu Z, Lian Y, et al. Modeling process-structureproperty relationships for additive manufacturing. Front Mech Eng 2018;13:482-92.

[5] Neiktera M, Åkerfeldta P, Pedersonb R, Anttia M, Sandella V. Microstructura characterization and comparison of Ti-6Al-4V manufactured with different additive manufacturing processes. Mater Charact 2018;134:68-75.

[6] Kasperovich G, Haubrich J, Gussone J, Requena G. Correlation between porosity and processing parameters in TiAl6V4 produced by selective laser melting. Mater Des 2016;105:160-70.

[7] Ren S, Chen Y, Liu T, Qu X. Effect of build orientation on mechanical properties and microstructure of Ti-6Al-4V manufactured by selective laser melting. Metall Mater Trans A 2019;50:4388-409.

[8] Leuders S, Thöne M, Riemer A, Niendorf T, Tröster T, Richard H, et al. On the mechanical behaviour of titanium alloy TiAl6V4 manufactured by selective laser melting: fatigue resistance and crack growth performance. Int J Fatigue 2013;48:300-7

[9] Åkerfeldt P, Pederson R, Antti M. A fractographic study exploring the relationship between the low cycle fatigue and metallurgical properties of laser metal wire deposited Ti-6Al-4V. Int J Fatigue 2016;87:245-56.

[10] Pegues J, Roach M, Williamson R, Shamsaei N. Surface roughness effects on the fatigue strength of additively manufactured Ti-6Al-4V. Int J Fatigue 2018;116:543-52.

[11] Fatemi A, Molaei R, Simsiriwong J, Sanaei N, Pegues J, Torries B, et al. Fatigue behaviour of additive manufactured materials: an overview of some recent experimental studies on Ti-6Al-4V considering various processing and loading direction effects. Fatigue Fract Eng Mater Struct 2019;42:991-1009.

[12] Kakiuchi T, Kawaguchi R, Nakajima M, Hojo M, Fujimoto K, Uematsu Y. Prediction of fatigue limit in additively manufactured Ti-6Al-4V alloy at elevated temperature. Int J Fatigue 2019;62:55-61.

[13] Wycisk E, Siddique S, Herzog D, Walther F, Emmelmann C. Fatigue performance of laser additive manufactured Ti-6 Al-4V in very high cycle fatigue regime up to $10^{9}$ cycles. Front Mater 2015;72(2):1-8.

[14] Günther J, Krewerth D, Lippmann T, Leuders S, Tröster T, Weidner A. Fatigue life of additively manufactured Ti-6Al-4V in the very high cycle fatigue regime. Int $\mathrm{J}$ Fatigue 2017;94:236-45.

[15] Tridello A, Fiocchi J, Biffi C, Chiandussi G, Rossetto M, Tuissi A, et al. VHCF response of heat-treated SLM Ti6Al4V Gaussian specimens with large loaded volume. Proc Struc Integ 2019;18:314-21.

[16] Murakami Y. Metal fatigue: effects of small defects and nonmetallic inclusions. Oxford, UK: Elsevier; 2002.
[17] Murakami Y. Material defects as the basis of fatigue design. Int J Fatigue $2012 \cdot 41: 2-10$.

[18] Paolino D, Chiandussi G, Rossetto M. A unified statistical model for S-N fatigue curves: probabilistic definition. Fatigue Fract Eng Mater Struct 2013;36:187-201.

[19] Paolino D, Tridello A, Chiandussi G, Rossetto M. Statistical estimation of duplex S-N curves. Key Eng Mater 2016;664:285-94.

[20] Paolino D, Tridello A, Chiandussi G, Rossetto M. S-N curves in the very-high-cycle fatigue regime: statistical modeling based on the hydrogen embrittlement consideration. Fatigue Fract Eng Mater Struct 2016;39:1319-36.

[21] Mine Y, Katashima S, Ding R, Bowen P, Takashima K. Fatigue crack growth behaviour in single-colony lamellar structure of Ti-6Al-4V. Scr Mater 2019;165:107-11.

[22] Pan X, Hong Y. High-cycle and very-high-cycle fatigue behaviour of a titanium alloy with equiaxed microstructure under different mean stresses. Fatigue Fract Eng Mater Struct 2019;42:1950-64.

[23] Pan X, Su H, Sun C, Hong Y. The behavior of crack initiation and early growth in high-cycle and very-high-cycle fatigue regimes for a titanium alloy. Int J Fatigue 2018;115:67-78.

[24] Hong Y, Sun C. The nature and the mechanism of crack initiation and early growth for very-high-cycle fatigue of metallic materials - an overview. Theor Appl Fract Mech 2017;92:331-50.

[25] Cao F, Ravi K. The role of crack origin size and early stage crack growth on high cycle fatigue of powder metallurgy Ti-6Al-4V alloy. Int J Fatigue 2017;102:48-58.

[26] Vayssette B, Saintier N, Brugger C, May M, Pessard E. Numerical modelling of surface roughness effect on the fatigue behavior of Ti-6Al-4V obtained by additive manufacturing. Int J Fatigue 2019;123:180-95.

[27] Yadollahi A, Mahtabi M, Khalili A, Doude H, Newman J. Fatigue life prediction of additively manufactured material: effects of surface roughness, defect size, and shape. Fatigue Fract Eng Mater Struct 2018;41:1602-14.

[28] Hong Y, Liu X, Lei Z, Sun C. The formation mechanism of characteristic region at crack initiation for very-high-cycle fatigue of high-strength steels. Int J Fatigue 2016;89:108-18

[29] Qian G, Jian Z, Pan X, Berto F. In-situ investigation on fatigue behaviors of Ti-6Al4V manufactured by selective laser melting. Int J Fatigue 2020;133:105424. https://doi.org/10.1016/j.ijfatigue.2019.105424.

[30] Xu S, Zhu S, Hao Y, Qian G. A new critical plane-energy model for multiaxial fatigue life prediction of turbine disc alloys. Eng Fail Anal 2018;93:55-63.

[31] Hu Y, Wu S, Wu Z, Zhong X, Ahmed S, Karabal S, et al. A new approach to correlate the defect population with the fatigue life of selective laser melted Ti-6Al-4V. Int J Fatigue 2020;136:105584https://doi.org/10.1016/j.ijfatigue.2020.105584.

[32] Liu X, Chen E, Zeng F, Cong T, Domblesky J. Mechanisms of interior crack initiation in very-high-cycle fatigue of high-strength alloys. Eng Fract Mech 2019;212:153-63.

[33] Qian G, Lei W. A statistical model of fatigue failure incorporating effects of specimen size and load amplitude on fatigue life. Philos Mag 2019;99:2089-125.

[34] Liao D, Zhu S, Qian G. Multiaxial fatigue analysis of notched components using combined critical plane and critical distance approach. Int J Mech Sc 2019;160:38-50.

[35] Cong T, Han J, Hong Y, Domblesky J, Liu X. Shattered rim and shelling of high speed railway wheels in the very-high-cycle fatigue regime under rolling contact loading. Eng Fail Anal 2019;97:556-67.

[36] Hu D, Wang T, Ma Q, Liu X, Shang L, Li D, et al. Effect of inclusions on low cycle fatigue lifetime in a powder metallurgy nickel-based superalloy FGH96. Int J Fatigue 2019;118:237-48

[37] Wang Z, Han J, Domblesky J, Li Z, Fan X, Liu. Crack propagation and microstructural transformation on the friction surface of a high-speed railway brake disc. Wear 2019;428-429:45-54. 